\title{
Formigas visitantes de inflorescências de Actinocephalus polyanthus (Bong.) Sano (Eriocaulaceae)
}

\author{
Elise Lara Galitzki ${ }^{1}$ \\ Carlos Eduardo Cereto ${ }^{2}$ \\ Karla Zanenga Scherer ${ }^{3}$ \\ Benedito Cortês Lopes ${ }^{3 *}$ \\ Tânia Tarabini Castellani ${ }^{3}$ \\ ${ }^{1}$ Departamento de Botânica, Centro de Ciências Biológicas, Universidade Federal de Santa Catarina \\ ${ }^{2}$ Universidade Federal da Fronteira Sul, Campus Universitário, Realeza - PR, Brasil \\ ${ }^{3}$ Departamento de Ecologia e Zoologia, Universidade Federal de Santa Catarina \\ Campus Universitário, Trindade, Caixa Postal 476, CEP 88040-900, Florianópolis - SC, Brasil \\ * Autor para correspondência \\ bclopes1@yahoo.com.br
}

Submetido em 17/07/2012

Aceito para publicação em 29/08/2013

\section{Resumo}

Plantas da família Eriocaulaceae apresentam uma secreção de néctar em estruturas florais que promove a visitação de insetos, inclusive formigas. Este estudo avaliou as espécies de formigas visitantes de inflorescências de Actinocephalus polyanthus em dunas costeiras no sul do Brasil e verificou se a riqueza e composição das assembleias visitantes diferiam entre as fenofases de floração feminina e masculina, em função da maior oferta de recurso por flores masculinas. Observações sobre o recurso utilizado e o comportamento de visita foram também investigados. Foram encontradas 15 espécies de formigas, pertencentes a oito gêneros de quatro subfamílias. Não houve diferença em relação à riqueza e diversidade de visitantes associadas à fenofase de floração masculina ou feminina. Entretanto, houve diferença em relação à similaridade dessas assembleias, em função da maior ocorrência de Camponotus fastigatus na floração feminina. A maioria das espécies registradas pertence a gêneros que, normalmente, utilizam néctar floral e extrafloral como recurso alimentar ou são generalistas. Brachymyrmex sp.1, Camponotus fastigatus e Dorymyrmex sp. foram observadas com pólen aderido ao corpo, o que sugere um potencial transporte desse pólen entre flores.

Palavras-chave: Dunas costeiras; Formicidae; Nectário floral; Poales; Visitantes florais

\section{Abstract}

Ants visiting inflorescences of Actinocephalus polyanthus (Bong.) Sano (Eriocaulaceae). Plants from the family Eriocaulaceae have a secretion of nectar in floral structures which promotes insect visitation, including ants. This study evaluated the ant species visiting inflorescences of Actinocephalus polyanthus in coastal dunes in southern Brazil and it checked whether the richness and composition of the visiting assemblies differed between the female and male flowering phenophases, due to the greater supply of resources by male flowers. Comments on the resources used and the visiting behavior were also investigated. We found 15 ant species, belonging to 
8 genera and 4 subfamilies. There was no difference with regard to richness and diversity of visiting species associated to the male or female flowering phenophase. However, there was a difference with regard to the similarity of these assemblies, due to the higher occurrence of Camponotus fastigatus in the female flowering. Most species registered belong to genera which, typically, use floral and extrafloral nectar as food resource or they are generalist. Brachymyrmex sp.1, Camponotus fastigatus, and Dorymyrmex sp. were observed with pollen stuck to their body, something which suggests a potential transportation of this pollen between flowers.

Key words: Coastal dunes; Floral nectary; Floral visitors; Formicidae; Poales

\section{Introdução}

Relações entre plantas e seus visitantes florais têm atraído o interesse dos naturalistas há bastante tempo (GÓMEZ, 2002). Além de buscar alimentos, muitos insetos utilizam flores como locais de proteção, caça, acasalamento e sítio de oviposição (MALERBOSOUZA et al., 2008). Embora existam teorias de que o pólen tenha sido o recurso original procurado pelos primeiros insetos, atualmente, o néctar é o recurso mais procurado e utilizado por esses animais (GÓMEZ; ZAMORA, 1992; LABANDEIRA, 1997).

As formigas (Hymenoptera: Formicidae) são um dos grupos de insetos que mais interagem com táxons vegetais, utilizando-os principalmente como fonte alimentar, seja pelo uso dos recursos florais e foliares, de nectários extraflorais, elaiossomos e sementes (HÖLLDOBLER; WILSON, 1990; GÓMEZ; ZAMORA, 1992; LOPES, 2005).

Contudo, mesmo presentes na maioria das comunidades como visitantes constantes de plantas e coletoras de néctar, existem poucos casos confirmados de polinização por formigas (RICO-GRAY; OLIVEIRA, 2007), normalmente restritos a hábitats áridos e quentes ou frios, ricos em plantas de pequeno porte e de distribuição agregada (HICKMAN, 1974; GÓMEZ; ZAMORA, 1992; DUTTON; FREDERICKSON, 2012). Formigas não são consideradas boas polinizadoras em função da secreção antimicrobiana das glândulas metapleurais que tornam os grãos de pólen inviáveis, além da pouca mobilidade entre plantas e da pequena quantidade de pólen que carregam (RICO-GRAY; OLIVEIRA, 2007; DUTTON; FREDERICKSON, 2012). Muitas vezes, as formigas são consideradas pilhadoras de néctar floral, pois removem o néctar das flores sem oferecer um benefício para as plantas (i.e. polinização).
A ordem Poales, que inclui a família Eriocaulaceae, reúne cerca de um terço das monocotiledôneas do mundo. Esta ordem é composta por espécies predominantemente polinizadas pelo vento, porém a síndrome de polinização por entomofilia ocorre em algumas famílias, como proposto para as Eriocaulaceae (LINDER; RUDALL, 2005). Esta família é caracterizada por possuir flores unissexuais pequenas reunidas em inflorescências capituliformes bissexuadas (MOLDENKE; SMITH, 1976), ocorrendo poucos casos de espécies dioicas (ROSA; SCATENA, 2007). Em Eriocaulaceae, algumas espécies apresentam secreção de néctar em estruturas presentes nas flores (ROSA; SCATENA, 2003; 2007) e, embora possa ocorrer auto-polinização, alguns estudos comprovam que a presença de néctar promove a visitação de insetos (RAMOS et al., 2005; ORIANI et al., 2009). Dentre estes, as formigas podem apresentar alta frequência de visita (ORIANI et al., 2009). Embora Rico-Gray e Oliveira (2007) não registrem formigas como polinizadoras de Eriocaulaceae, Oriani et al. (2009) descrevem formigas como polinizadores efetivos ou ocasionais de Syngonanthus elegans com base em sua elevada frequência e comportamento de visita, que evidenciam a capacidade de transportar pólen entre plantas e contactar o estigma.

Actinocephalus polyanthus possui estruturas secretoras de néctar tanto em flores estaminadas quanto em pistiladas (ROSA; SCATENA, 2007). Nesta espécie, as flores estaminadas ocorrem em número três vezes maior que as flores femininas por capítulo (CASTELLANI; D'EÇA-NEVES, 2000). Em um mesmo capítulo, a abertura das flores inicia-se com a antese das masculinas, seguidas das femininas e novamente das masculinas (D’EÇA-NEVES; CASTELLANI, 1994; CASTELLANI; D'EÇA-NEVES, 2000). 
Considerando que a oferta de recursos florais oferecidos por $A$. polyanthus varia entre flores estaminadas e pistiladas (i.e. flores masculinas oferecem néctar e pólen e são mais abundantes que as femininas que oferecem apenas néctar) e que a presença de formigas foi observada em suas inflorescências (ARRUDA et al., 2003), o presente estudo tem como objetivos: (1) realizar um levantamento das espécies de formigas visitantes de inflorescências desta Eriocaulaceae, (2) avaliar se há diferenças nas assembleias de visitantes em função das fenofases femininas e masculinas e (3) observar as espécies de formigas quanto ao seu comportamento de visita.

\section{Material e Métodos}

\section{Área de estudo}

Este trabalho foi realizado no setor norte do Parque Municipal das Dunas da Lagoa da Conceição, em uma área de $4 \mathrm{~km}^{2}$, situada a $500 \mathrm{~m}$ da lagoa, Ilha de Santa Catarina, SC (27³6’40”'S e 48 $27^{\circ} 10^{\prime}$ 'O). A área comporta dunas fixas e semi-fixas, entremeadas por baixadas úmidas alagáveis em algumas épocas do ano (CASTELLANI et al., 2001), sendo a vegetação local predominantemente herbácea. O clima da região é do tipo mesotérmico úmido, Cfa de Koeppen, com temperatura média anual de $20^{\circ} \mathrm{C}$ e média pluviométrica anual de $1738 \mathrm{~mm}$. Nos períodos de outono e inverno há redução da pluviosidade podendo ocorrer déficit hídrico (GÜTSCHOW-BENTO et al., 2010).

\section{Espécie em estudo}

Actinocephalus polyanthus (Bong.) Sano é uma Eriocaulaceae que, no estado de Santa Catarina, ocorre nos campos do planalto e nos campos arenosos litorâneos (MOLDENKE; SMITH, 1976). É uma espécie herbácea, monocárpica (CASTELLANI et al., 2001), com cerca de 200 capítulos florais por umbela, estas ocorrendo em número médio de oito por planta (CASTELLANI; D'EÇA-NEVES, 2000). As flores estaminadas (masculinas) apresentam três pistilódios nectaríferos na porção central do receptáculo floral e as flores pistiladas (femininas) possuem estaminódios escamiformes, em número de três, inseridos na região basal do gineceu. Este apresenta estilete oco, ramificado com porções estigmática e nectarífera (ROSA; SCATENA, 2007). A fase reprodutiva iniciase em junho com a formação dos capítulos florais, com floração de julho a janeiro e pico em novembro (D'EÇANEVES; CASTELLANI, 1994). Na área de estudo, a espécie ocorre nas baixadas entre dunas, apresentando distribuição agregada (MOLDENKE; SMITH, 1976; CASTELLANI et al., 2001), podendo ocorrer o contato entre as umbelas (CASTELLANI; D’EÇA-NEVES, 2000) do mesmo indivíduo ou entre indivíduos diferentes (GALITZKI, 2009).

\section{Coleta de dados}

Para a avaliação da assembleia de formigas visitantes foram realizadas dez saídas de campo, com duração aproximada de três horas cada, no período entre $9 \mathrm{~h}$ e $12 \mathrm{~h}$, entre os meses de agosto e dezembro de 2008. Em cada amostragem foi avaliada uma média de 20 plantas, totalizando 194 indivíduos reprodutivos. Em cada saída, foi estabelecida uma rota distinta para a amostragem e, a cada $15 \mathrm{~m}$ lineares, sorteava-se uma distância de $2 \mathrm{~m}$ para a esquerda ou direita para amostrar as duas plantas em floração mais próximas e também a mais próxima na fenofase de botão (nos meses de agosto, setembro e outubro) ou frutificação (nesse caso, novembro e dezembro). A avaliação de plantas em botão ou em frutificação foi feita para investigar se a presença de formigas era ocasional ou direcionada à coleta de néctar, isto é, nas plantas em floração. Em cada planta todas as umbelas foram observadas quanto à fenofase (quando em floração, se masculina ou feminina) e para o registro e coleta das formigas presentes. Todas as formigas presentes nas inflorescências, observadas utilizando néctar e/ou pólen ou com grãos de pólen aderidos ao corpo, foram coletadas.

As formigas visitantes das inflorescências foram coletadas com ajuda de pincel embebido em álcool e acondicionadas em frascos contendo álcool $70 \%$. Após montagem, as formigas foram identificadas com base na chave para subfamílias e gêneros de Palacio e Fernández (2003), em chaves para espécies, assim como na comparação com exemplares presentes da coleção 
do Laboratório de Biologia de Formigas do Centro de Ciências Biológicas da UFSC.

\section{Análise de dados}

Foi calculada, para cada fenofase, a frequência de ocorrência de cada espécie de formiga. Foi construída uma curva de acumulação de espécies (Mao Tau) e respectivos intervalos de confiança $(95 \%)$ para avaliar a riqueza de espécies de formigas amostradas em plantas com inflorescência em fenofase masculina ou feminina, utilizando-se o programa EstimateS (COLWELL, 2006). Foram calculados os índices de diversidade de Simpson para estas assembleias de formigas visitantes, sendo comparados pelo teste t (BROWER et al., 1998). A semelhança da composição destas assembleias foi avaliada por análise de similaridade (ANOSIM) (CLARKE, 1993), utilizando a dissimilaridade de Jaccard. Foi aplicado um teste de Qui-quadrado (ZAR, 1999) para verificar se a frequência de cada espécie de formiga diferia entre a fenofase masculina ou feminina. De forma complementar, a análise de espécie indicadora (IndVal) (DUFRÊNE; LEGENDRE, 1997) foi utilizada para verificar as espécies características de cada fenofase. As análises de ANOSIM e IndVal foram realizadas no programa $R$ (R DEVELOPMENT CORE TEAM, 2012). O parâmetro quantitativo considerado nestas análises foi o número de ocorrências de cada espécie nas plantas amostradas e não o número total de indivíduos de formigas. Este procedimento é usual em estudos de comunidades de formigas, em função de diferenças no comportamento social de forrageio e de recrutamento de operárias (LEAL et al., 1993).

\section{Resultados}

Das 194 plantas amostradas, 42 encontravamse na fenofase de botão, 85 com flores masculinas em antese, 38 com flores femininas, 11 com flores masculinas e femininas abertas simultaneamente e 18 com frutos já formados. Das 134 plantas em floração, 78 (58\%) apresentavam pelo menos uma espécie de formiga em suas inflorescências. Das plantas em botão e em frutificação, apenas uma apresentava formigas.
Nestas plantas foram encontradas 15 espécies de formigas, pertencentes a quatro subfamílias e oito gêneros, sendo Camponotus o gênero mais rico, com cinco espécies. Todas as espécies foram registradas em inflorescências masculinas. Nove espécies ocorreram também em inflorescências femininas e seis em plantas com flores femininas e masculinas simultaneamente (Tabela 1).

Considerando o total de plantas amostradas em floração (masculinas e/ou femininas) $(\mathrm{n}=134)$, as espécies com maior frequência de ocorrência foram Camponotus fastigatus (19,4\%), Dorymyrmex sp. (17,2\%), Brachymyrmex sp.1 (15,7\%) e Linepithema micans $(10,5 \%)$. Para as plantas amostradas na fenofase de botão e fruto, apenas as espécies Dorymyrmex sp. e Linepithema micans, respectivamente, foram observadas.

Considerando apenas as plantas com inflorescências masculinas $(n=85)$ e femininas $(n=38)$, em $56,5 \%$ e $63,2 \%$ destas plantas, respectivamente, foi registrada a presença de formigas. Quanto à riqueza de espécies de formigas visitantes, as curvas de acumulação não sugerem uma diferença associada às fenofases masculina e feminina (Figura 1). No entanto, para a fenofase masculina, que se mostrou mais frequente durante a floração, as curvas de acumulação mostram uma tendência de aumento de espécies de formigas associadas. Para a fenofase feminina, a curva de acumulação tendeu à estabilização (Figura 1).

Não houve diferença significativa nos índices de diversidade obtidos para as assembleias de formigas visitando inflorescências masculinas e femininas $\left(D_{\text {masc }}\right.$ $=0,86$ e $\left.\mathrm{D}_{\text {fem }}=0,82 ; \mathrm{t}=0,85 ; \mathrm{p}>0,05\right)$. As espécies Camponotus rufipes, Camponotus sp.2 e Solenopsis sp. ocorreram exclusivamente em plantas com flores masculinas, porém em baixa frequência, o que gerou uma pequena diferença entre as duas assembleias de formigas $(\mathrm{R}=0,06 ; \mathrm{p}=0,03)$. Somente Camponotus fastigatus mostrou frequência de visitação diferente de acordo com a fenofase da inflorescência $\left(\mathrm{X}^{2}=7,41\right.$, $\mathrm{p}=0,007 ; \mathrm{gl}=1)$, sendo mais frequente na fenofase feminina (Tabela 1). 
TABELA 1: Frequência de ocorrência (\%) de espécies de formigas em plantas de Actinocephalus polyanthus (Eriocaulaceae) em diferentes fenofases, no Parque Municipal das Dunas da Lagoa da Conceição, Ilha de Santa Catarina, SC. ( $\mathrm{n}=$ número de plantas amostradas em cada fenofase) e $[\mathrm{n}=$ número de plantas com a ocorrência da espécie de formiga].

\begin{tabular}{|c|c|c|c|c|c|}
\hline \multirow[b]{2}{*}{ Subfamília/Espécies } & \multirow[b]{2}{*}{$\begin{array}{c}\text { Botão } \\
(\mathrm{n}=42)\end{array}$} & \multicolumn{3}{|c|}{ Flor } & \multirow[b]{2}{*}{$\begin{array}{c}\text { Fruto } \\
(\mathrm{n}=18)\end{array}$} \\
\hline & & $\begin{array}{l}\text { Masculina } \\
\quad(\mathrm{n}=\mathbf{8 5})\end{array}$ & $\begin{array}{c}\text { Feminina } \\
(\mathbf{n}=\mathbf{3 8})\end{array}$ & $\begin{array}{c}\text { Masculina e } \\
\text { Feminina } \\
(\mathrm{n}=11)\end{array}$ & \\
\hline \multicolumn{6}{|l|}{ Dolichoderinae } \\
\hline Dorymyrmex sp. & $2,4[1]$ & $18,8[16]$ & $13,2[5]$ & $18,2[2]$ & - \\
\hline Linepithema micans & - & $9,4[8]$ & $15,8[6]$ & - & $5,6[1]$ \\
\hline Linepithema sp. & - & $1,2[1]$ & $5,3[2]$ & - & - \\
\hline \multicolumn{6}{|l|}{ Formicinae } \\
\hline Brachymyrmex sp.1 & - & $20,0[17]$ & 7,9 [3] & $9,1[1]$ & - \\
\hline Brachymyrmex sp.2 & - & $2,4[2]$ & - & $9,1[1]$ & - \\
\hline Camponotus fastigatus & - & $11,8[10]$ & $34,7[13]$ & $27,3[3]$ & - \\
\hline Camponotus melanoticus & - & $1,2[1]$ & $2,6[1]$ & - & - \\
\hline Camponotus rufipes & - & $2,4[2]$ & - & - & - \\
\hline Camponotus sp.1 & - & $1,2[1]$ & - & $9,1[1]$ & - \\
\hline Camponotus sp.2 & - & $1,2[1]$ & - & - & - \\
\hline Myrmelachista sp. & - & $2,4[2]$ & $5,3[2]$ & - & - \\
\hline \multicolumn{6}{|l|}{ Myrmicinae } \\
\hline Solenopsis sp. & - & $1,2[1]$ & - & - & - \\
\hline Wasmannia auropunctata & - & $4,7[4]$ & - & $9,1[1]$ & - \\
\hline \multicolumn{6}{|l|}{ Pseudomyrmecinae } \\
\hline Pseudomyrmex gracilis & - & $3,5[3]$ & $2,6[1]$ & - & - \\
\hline Pseudomyrmex sp. & - & $1,2[1]$ & $5,3[2]$ & - & - \\
\hline
\end{tabular}

FIGURA 1: Curvas de acumulação de espécies de formigas visitantes de inflorescências masculinas (preto) e femininas (cinza) de Actinocephalus polyanthus (Eriocaulaceae) e respectivos intervalos de confiança (95\%) no Parque Municipal das Dunas da Lagoa da Conceição, Ilha de Santa Catarina, SC.

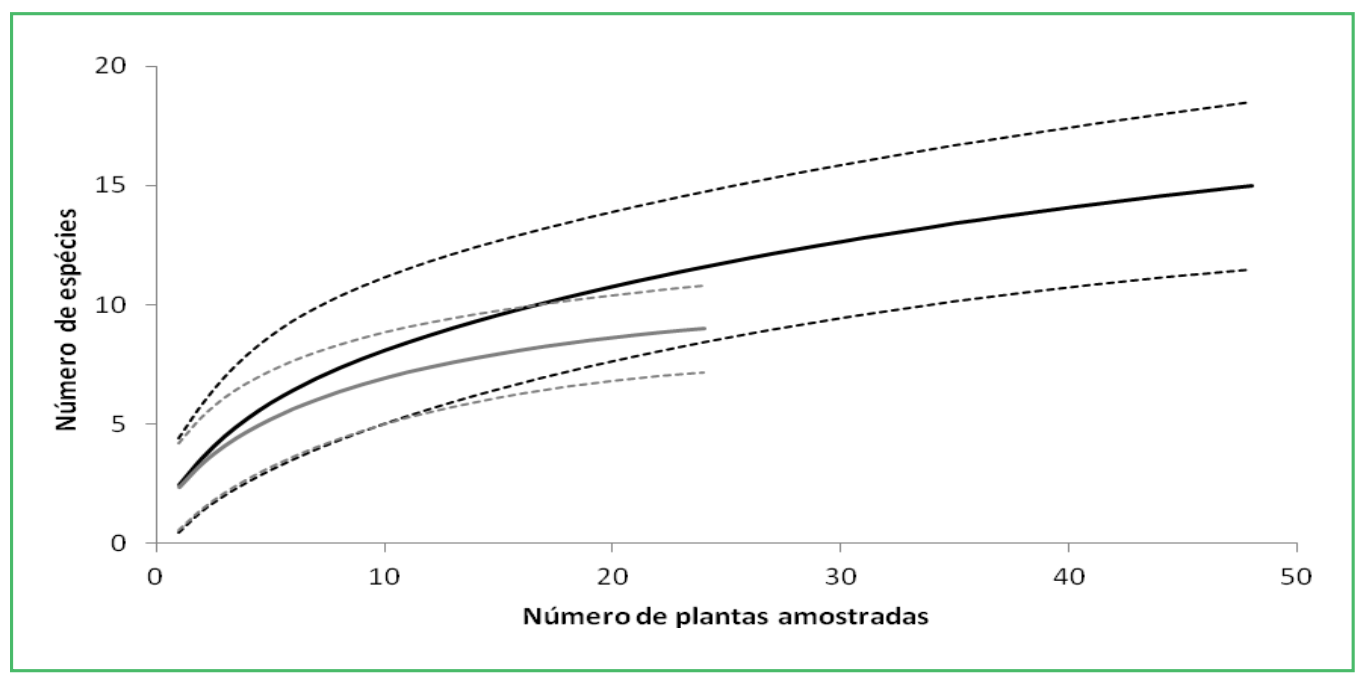


A análise de espécie indicadora (INDVAL $=0,47$; $\mathrm{p}=0,002)$ reforça esta tendência, sendo $C$. fastigatus indicadora da fenofase feminina. Todas as espécies registradas em inflorescências foram observadas utilizando néctar, nas nenhuma espécie foi registrada comendo pólen. Ademais, foi possível observar para as espécies mais frequentes (Brachymyrmex sp.1, Camponotus fastigatus e Dorymyrmex sp.), o comportamento de tocar as anteras das flores masculinas ao visitarem as inflorescências, provocando a transferência de pequena quantidade de pólen para seus corpos. A Figura 2 ilustra este comportamento com $C$. fastigatus.

FIGURA 2: Camponotus fastigatus, visitante floral de Actinocephalus polyanthus (Eriocaulaceae) no Parque Municipal das Dunas da Lagoa da Conceição, Ilha de Santa Catarina, SC. A) vista geral da inflorescência com duas operárias e B) detalhe das operárias com pólen aderido ao corpo.
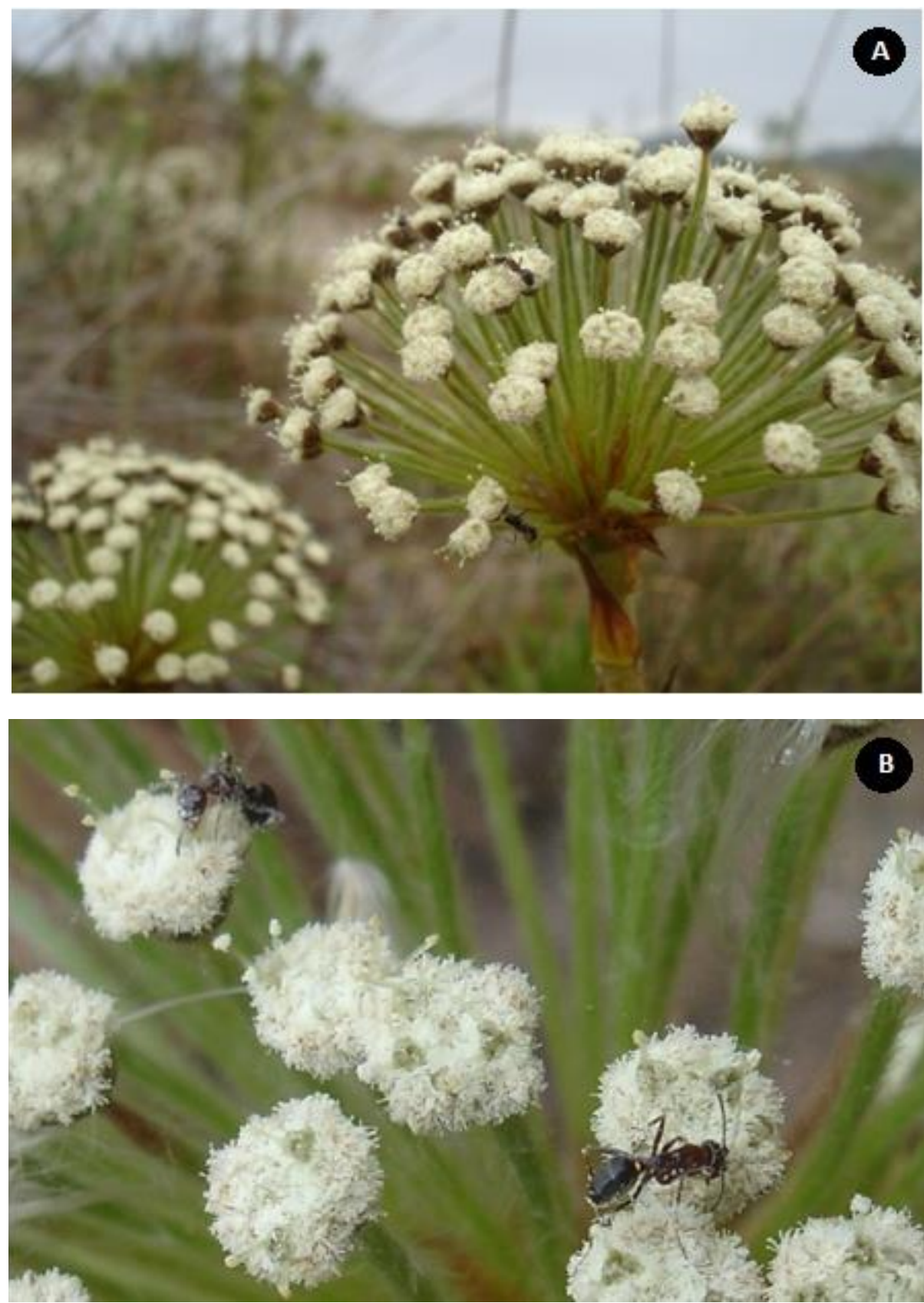


\section{Discussão}

Quinze espécies de formigas visitaram inflorescências de Actinocephalus polyanthus, a maioria utilizando-se do néctar oferecido, havendo uma pequena diferença na assembleia de formigas visitantes de flores masculinas e femininas. A riqueza de espécies de formigas visitantes de inflorescências de Actinocephalus polyanthus pode ser considerada elevada quando comparada a estudos anteriores sobre visitantes florais de outras espécies de Eriocaulaceae. Ramos et al. (2005) encontraram para duas espécies de Syngonanthus em campo rupestre (Chapada Diamantina, BA), 19 espécies de insetos visitantes, porém sem representantes da família Formicidae. Em um estudo com Syngonanthus elegans (ORIANI et al., 2009), em campo rupestre da Serra do Cipó (MG), foram registrados 29 visitantes florais e, dentre estes, apenas três espécies de formigas. Esta diferença de riqueza pode refletir a abordagem do presente estudo, que é o primeiro trabalho voltado completamente à visitação de formigas em flores de Eriocaulaceae. Isto permitiu um levantamento de espécies mais detalhado, o que mostra a representatividade destes visitantes aos recursos oferecidos nas inflorescências de Eriocaulaceae.

O número de espécies de formigas associadas a inflorescências de Actinocephalus polyanthus é também elevado quando se considera a riqueza de formigas em ambiente de restinga. Bonnet e Lopes (1993) registraram 33 espécies de formigas para esta mesma localidade (Parque Municipal das Dunas da Lagoa da Conceição); Cereto (2008) registrou 80 espécies em diferentes fitofisionomias (herbácea, arbustiva e arbórea) em restinga mais ao sul do Parque e Vargas et al. (2007), em restinga no estado do Rio de Janeiro, encontraram 92 espécies. Nestes estudos, as formigas foram coletadas com iscas de sardinha, por coleta ativa ou com armadilhas tipo pitfall. Assim, o número de 15 espécies encontradas visitando $A$. polyanthus é relativamente alto, já que estas foram coletadas em uma situação bastante específica, associadas a uma única espécie de planta.

Os gêneros de formigas encontrados visitando as inflorescências de $A$. polyanthus são, em sua maioria, generalistas quanto ao hábito alimentar (BROWN,
1973; SILVESTRE et al., 2003). Operárias dos gêneros Dorymyrmex (CUEZZO, 2003), Brachymyrmex (FERNÁNDEZ, 2003a), Solenopsis e Wasmannia (FERNÁNDEZ, 2003b), embora sejam mais comuns no solo ou na serapilheira, podem subir até a vegetação para se alimentar de néctar e pólen. Assim, mesmo aqueles gêneros que não estão comumente associados à vegetação, apresentam indivíduos que forrageiam nas inflorescências de A. polyanthus.

As espécies com maior frequência de ocorrência em nosso estudo (Camponotus fastigatus, Dorymyrmex sp., Brachymyrmex sp.1 e Linepithema micans) pertencem a gêneros frequentes em restinga (VARGAS et al., 2007; CERETO, 2008).

Díaz-Castelazo et al. (2004), em estudo envolvendo plantas com nectários extraflorais na costa mexicana, sugerem como potenciais forrageadoras de néctar as espécies dos gêneros Brachymyrmex, Camponotus, Dorymyrmex, Pseudomyrmex, Solenopsis e Wasmannia, gêneros que também foram registrados nas inflorescências de $A$. polyanthus utilizando néctar. Desta forma, o comportamento das espécies encontradas nas inflorescências de $A$. polyanthus é condizente ao descrito para os gêneros aos quais pertencem.

Pseudomyrmex e Myrmelachista são gêneros muito associados a plantas (WHEELER, 1934; FERNÁNDEZ, 2003a; WARD, 2003). Uma das espécies encontradas, Pseudomyrmex gracilis, frequentemente utiliza nectários extraflorais, além de predar outros invertebrados, o que inclui formigas do gênero Camponotus (DANSA, 1989). Espécies de Camponotus foram encontradas visitando inflorescências de $A$. polyanthus, sendo plausível que $P$. gracilis ao visitarem as inflorescências de $A$. polyanthus possam estar consumindo néctar ou em busca de outros artrópodes.

Apesar do maior número de flores masculinas presentes por capítulo floral, o levantamento realizado não evidenciou diferença entre a riqueza e diversidade de espécies de formigas visitantes de inflorescências masculinas e femininas de A. polyanthus, assim como a frequência de formigas em plantas em fase masculina e feminina foi muito similar. Uma média de 15,2 flores masculinas e 5,5 flores femininas é registrada por 
capítulo (D’EÇA-NEVES; CASTELLANI, 2000). Apesar desta diferença de oferta de recurso, flores femininas são um recurso muito abundante para as formigas, podendo uma umbela produzir cerca de 205,3 capítulos desenvolvidos com cerca de 1129 flores femininas. Por planta, esta oferta chega a 9032 flores em média (D’EÇA-NEVES; CASTELLANI, 2000). Quanto à composição das assembleias de formigas, ocorreu diferença, devido à maior ocorrência de Camponotus fastigatus em inflorescências da fenofase feminina.

Apesar de serem raras e específicas as ocasiões em que formigas atuam como polinizadoras (HICKMAN, 1974; DUTTON; FREDERICKSON, 2012), pode-se destacar o comportamento das formigas que, ao visitarem as inflorescências de $A$. polyanthus tocam as anteras, provocando a transferência de pequena quantidade de pólen para seus corpos. Assim, ao visitarem inflorescências femininas, estas formigas poderiam vir a realizar o transporte do pólen de uma planta para outra. Oriani et al. (2009) consideraram Solenopsis sp. como polinizadora efetiva de Syngonanthus elegans com base na frequência de visitas, comportamento junto aos capítulos e grãos de pólen aderidos ao corpo desta formiga. Apesar da necessidade de testes envolvendo a viabilidade dos grãos de pólen (DUTTON; FREDERICKSON, 2012), no presente estudo, e usando os mesmos critérios de Oriani et al. (2009), podemos sugerir o potencial das espécies Brachymyrmex sp.1, Camponotus fastigatus, Dorymyrmex sp. como eventuais polinizadoras de Actinocephalus polyanthus. Especial atenção deve ser dada para a investigação futura da viabilidade do pólen aderido a Camponotus fastigatus, uma vez que esta espécie apresentou alta frequência de visitação às flores femininas, apresentando pólen aderido ao corpo. Aliado a estes fatos, neste gênero a glândula metapleural pode estar ausente (JOHNSON et al., 2003), e dessa maneira, não haveria o comprometimento da viabilidade dos grãos de pólen por parte das secreções antibióticas desta glândula.

Em A. polyanthus, as flores estaminadas apresentam três pistilódios nectaríferos na porção central do receptáculo floral e as flores pistiladas possuem porções nectaríferas no estilete (ROSA; SCATENA, 2007). Em flores jovens, as porções nectaríferas são mais longas que as estigmáticas, enquanto que em flores adultas esta relação se inverte. Esta característica sugere que, em flores maduras, um visitante em busca de néctar provavelmente toca os estames da flor para acessar tal recurso. Assim, se este visitante estiver carregando pólen, pode vir a transferi-lo aos pistilos da flor visitada, funcionando assim como potencial polinizador (ROSA; SCATENA, 2007; ORIANI et al., 2009).

Hickman (1974) e Gómez e Zamora (1992) sugerem que a polinização por formigas ocorreria em hábitats secos e quentes, em plantas com nectários pequenos que não despertem o interesse de visitantes de grande porte; flores pequenas, actinomórficas e expostas com atrativos visuais mínimos; poucas flores em antese ao mesmo tempo; pequena quantidade de pólen pegajoso e poucos óvulos por flor. Destas características, destacase que A. polyanthus ocorre em habitat seco e quente, apresenta flores e nectários pequenos, porém suas flores estão organizadas em inflorescências com numerosos capítulos florais, que exercem grande atração para formigas e demais insetos. Por outro lado, Rico-Gray e Oliveira (2007), ao comentarem Hickman (1974), acrescentam como características relevantes para a polinização por formigas um porte baixo das plantas, uma distribuição agrupada, com inflorescências que se tocam. Todas estas características estão presentes na população de $A$. polyanthus estudada (MOLDENKE; SMITH, 1976; CASTELLANI; D’EÇA-NEVES, 2000; CASTELLANI et al., 2001).

Gómez et al. (1996) mencionam que os sistemas que envolvem polinização por formigas são provenientes de condições ecológicas que envolvem flores e pequenos insetos, mas sem interações muito especializadas. Formigas têm sido consideradas polinizadoras principalmente em função da alta frequência de visitas às flores (GÓMEZ; ZAMORA, 1992; RICOGRAY; OLIVEIRA, 2007). Apesar de, durante as observações em campo, não ter sido observado nenhum comportamento agressivo das formigas em relação a potenciais polinizadores de A. polyanthus (borboletas, abelhas ou moscas), sugere-se que sejam avaliadas as interações entre esses grupos. Além disso, recomendase que estudos que envolvam a avaliação de viabilidade 
de pólen em formigas visitantes de Eriocaulaceae, assim como um melhor entendimento de seu sistema reprodutivo sejam realizados.

\section{Agradecimentos}

À Érika Tsuda pelo auxílio no uso dos scripts do Programa R.

\section{Referências}

ARRUDA, V. L. V.; CASTELLANI, T. T.; LOPES, B. C. Formigas em plantas de restinga: os estudos na Ilha de Santa Catarina. In: SIMPÓSIO DE MIRMECOLOGIA, 16, 2003, Florianópolis. Resumos... Florianópolis: UFSC, 2003. p. 386-391.

BONNET, A.; LOPES, B. C. Formigas de dunas e restingas na praia da Joaquina, Ilha de Santa Catarina, SC (Insecta: Hymenoptera). Biotemas, Florianópolis v. 6, n. 1, p. 107-114, 1993.

BROWER, J. E.; ZAR, J. H.; ENDE, C. N. Field and laboratory methods for general ecology. 4. ed. Boston: WCB McGraw-Hill, 1998. 273 p.

BROWN, W. L. JR. A comparison of the Hylean and Congo-West African rain forest ant faunas. In: MEGGERS, B. J.; AYENSU, E. S.; DUCKWORT, W. D. (Ed.). Tropical forest ecosystems in Africa and South America: a comparative review. Washington: Smithsonian Institute Press, 1973. p. 161-185.

CASTELlANI, T. T.; D’EÇA-NEVES, F. F. Population ecology of Paepalanthus polyanthus: predispersal hazards and seed production. Acta Botanica Brasilica, São Paulo, v. 14, n. 3, p. 317326, 2000.

CASTEllani, T. T.; SCHERER, K. Z.; PAUlA, G. de S. Population ecology of Paepalanthus polyanthus (Bong.) Kunth: demography and life history of a sand dune monocarpic plant. Revista Brasileira de Botânica, São Paulo, v. 24, n. 2, p. 123-134, 2001.

CERETO, C. E. Formigas em restinga na região da Lagoa Pequena, Florianópolis, SC: levantamento taxonômico e aspectos ecológicos. 2008. 95 f. Monografia (Trabalho de Conclusão de Curso de Graduação em Ciências Biológicas) - Universidade Federal de Santa Catarina, Florianópolis. 2008.

CLARKE, K. R. Non-parametric multivariate analysis of changes in community structure. Australian Journal of Ecology, Carlton, v. 18, n. 1, p. 117-143, 1993.

COLWELL, R. K. EstimateS (Statistical estimates of species richness and shared species samples). Version 7.5.2. 2006.

DANSA, C. V. A Estratégia de forrageamento de Pseudomyrmex gracilis (Fabr.) (Hymenoptera: Formicidae). 1989. $131 \mathrm{f}$. Dissertação (Mestrado em Ecologia) - Universidade Estadual de Campinas, Campinas. 1989.

D'EÇA-NEVES, F. F.; CASTELLANI, T. T. Fenologia e aspectos reprodutivos de Paepalanthus polyanthus (Bong.) Kunth (Eriocaulaceae) em baixada úmida entre dunas na Praia da Joaquina, Ilha de Santa Catarina, SC. Ínsula, Florianópolis, v. 23, p. 121-149, 1994.

DÍAZ-CASTELAZO, C.; RICO-GRAY, V.; OLIVEIRA, P. S.; CUAUTLE, M. Extrafloral nectary-mediated ant-plant interactions in the coastal vegetation of Veracruz, Mexico: richness, occurrence, seasonality, and ant foraging patterns. Écoscience, Québec, v. 11, n. 4, p. 472-481, 2004.

DUFRÊNE, M.; LEGENDRE, P. Species assemblages and indicator species: the need for a flexible asymmetrical approach. Ecological Monographs, Ithaca, v. 67, n. 3, p. 345-366. 1997.

DUTTON, E. M; FREDERICKSON, M. E. Why ant pollination is rare: new evidence and implications of the antibiotic hypothesis. Arthropod-Plant Interactions, Basel, v. 6, n. 4, p. 561-569, 2012. FERNÁNDEZ, F. Subfamília Formicinae. In: FERNÁNDEZ, F. (Ed.). Introducción a las hormigas de la región Neotropical. Bogotá: Instituto de Investigación de Recursos Biológicos Alexander von Humboldt, 2003a. p. 299-306.

FERNÁNDEZ, F. Subfamília Myrmicinae. In: FERNÁNDEZ, F. (Ed.). Introducción a las hormigas de la región Neotropical. Bogotá: Instituto de Investigación de Recursos Biológicos Alexander von Humboldt, 2003b. p. 307-330.

GALITZKI, E. L. Utilização de recursos florais de Actinocephalus polyanthus (Bong.) Sano (Eriocaulaceae) por formigas na praia da Joaquina, Florianópolis, SC. 2009. 38 f. Trabalho de Conclusão de Curso (Bacharelado em Ciências Biológicas) - Universidade Federal de Santa Catarina, Florianópolis. 2009.

GÓMEZ, J. M. Generalización en las interacciones entre plantas y polinizadores. Revista Chilena de História Natural, Santiago, v. 75, n. 1, p. 105-116, 2002.

GÓMEZ, J. M.; ZAMORA, R. Pollination by ants: consequences of the quantitative effects on a mutualistic system. Oecologia, Heidelberg, v. 91, n. 3, p. 410-418, 1992.

GÓMEZ, J. M.; ZAMORA, R.; HÓDAR, J. A.; GARCÍA, D. Experimental study of pollination by ants in Mediterranean high mountain and arid habitats. Oecologia, Heidelberg, v. 105, n. 2, p. 236-242, 1996.

GÜTSCHOW-BENTO, L. H.; CASTELLANI, T. T.; LOPES, B. C.; GODINHO, P. S. Estratégia de crescimento clonal e fenologia de Syngonanthus chrysanthus Ruhland (Eriocaulaceae) nas baixadas entre dunas da Praia da Joaquina, Florianópolis, SC, Brasil. Acta Botanica Brasilica, São Paulo, v. 24, n. 1, p. 205-213, 2010.

HICKMAN, J. C. Pollination by ants: a low-energy system. Science, New York, v. 184, n. 4143, p. 1290-1292, 1974.

HÖLldoBler, B.; WILSON, E. O. The ants. Cambridge: Harvard University Press, 1990. 732 p.

JOHNSON, R. N.; AGAPOW, P-H.; CROZIER, R. H. A tree island approach to inferring phylogeny in the ant subfamily Formicinae, with special reference to the evolution of weaving. Molecular Phylogenetics and Evolution, New York, v. 29, n. 2, p. 317-330, 2003.

KREBS, C. J. Ecological methodology. New York: Harper \& Row, 1989. $654 \mathrm{p}$.

LABANDEIRA, C. C. Permian pollen eating. Science, New York, v. 277, n. 5331, p. 1421-1423, 1997.

LEAL, I. R.; FERREIRA, S. de O.; FREITAS, A. V. L. Diversidade de formigas de solo em um gradiente sucessional de Mata Atlântica, ES, Brasil. Biotemas, Florianópolis, v. 6, n. 2, p. 42-53, 1993. 